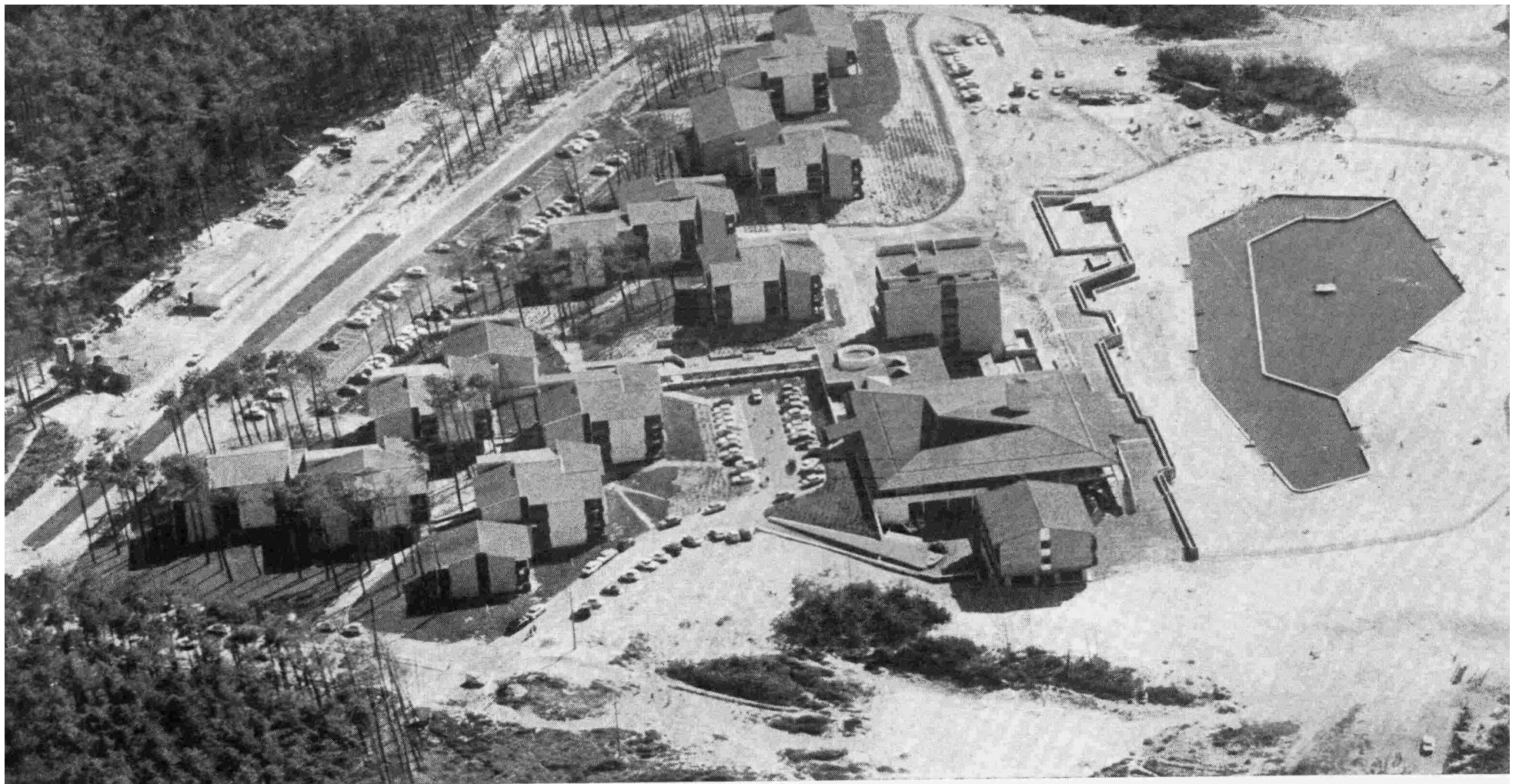

Foto: H. FITTE

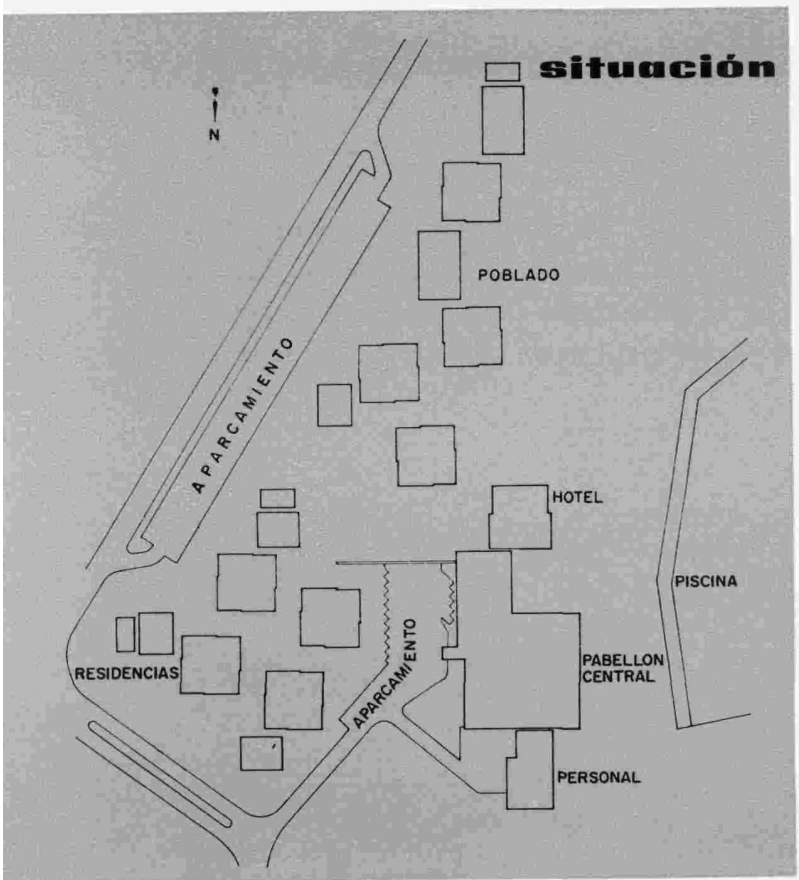

\title{
poblado de vacaciones en Seignosse le Penon - Francia
}

AQUITAINE ARCHITECTES ASSOCIES $y$

J. R. HEBRARD, A. GRESY y J. PERCILLIER, arquitectos D. P. L. G.

$161-153$

\section{sinopsis}

Este conjunto urbanístico consta de: un grupo de 125 apartamentos, de 2 habitaciones, sin cocina; 124 apartamentos, de 2 habitaciones, con cocina; un hotel de 6 plantas, destinado a alojar jóvenes familias; un pabellón central, que alberga los salones y las dependencias en las que se desarrollan actividades de tipo comunitario; una gran piscina de agua salada; alojamientos para empleados; etc.

Las familias que vienen a pasar aquí sus vacaciones estivales pueden disfrutar de toda clase de comodidades. El resto del año, el conjunto es utilizado para la celebración de congresos y seminarios. Es ocupado, asimismo, por personas jubiladas que aprovechan determinadas épocas del año para gozar de unos merecidos y gratos descansos.

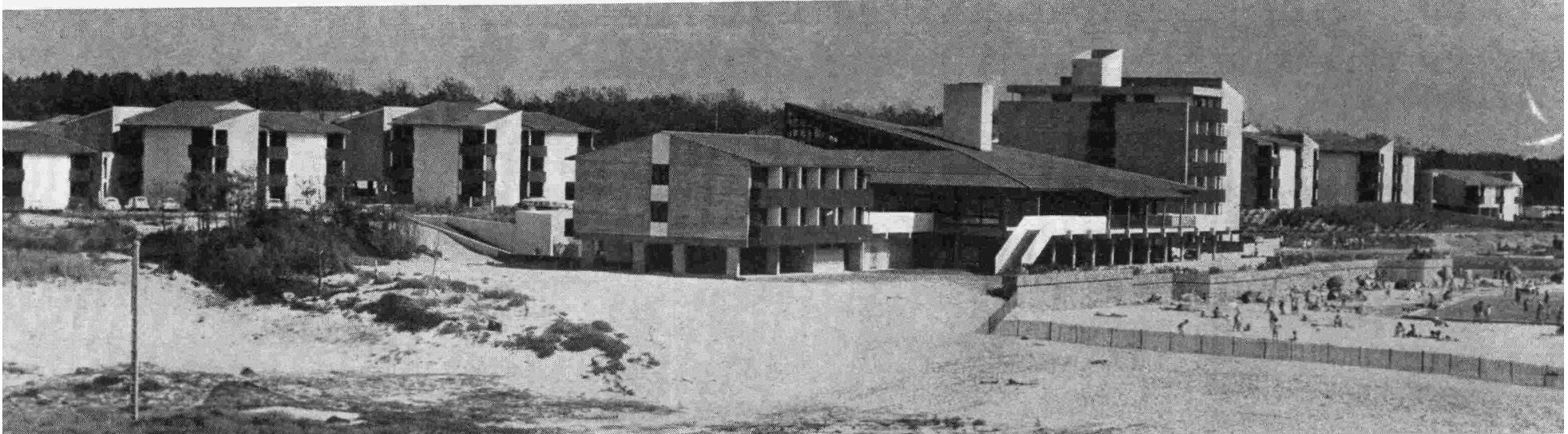




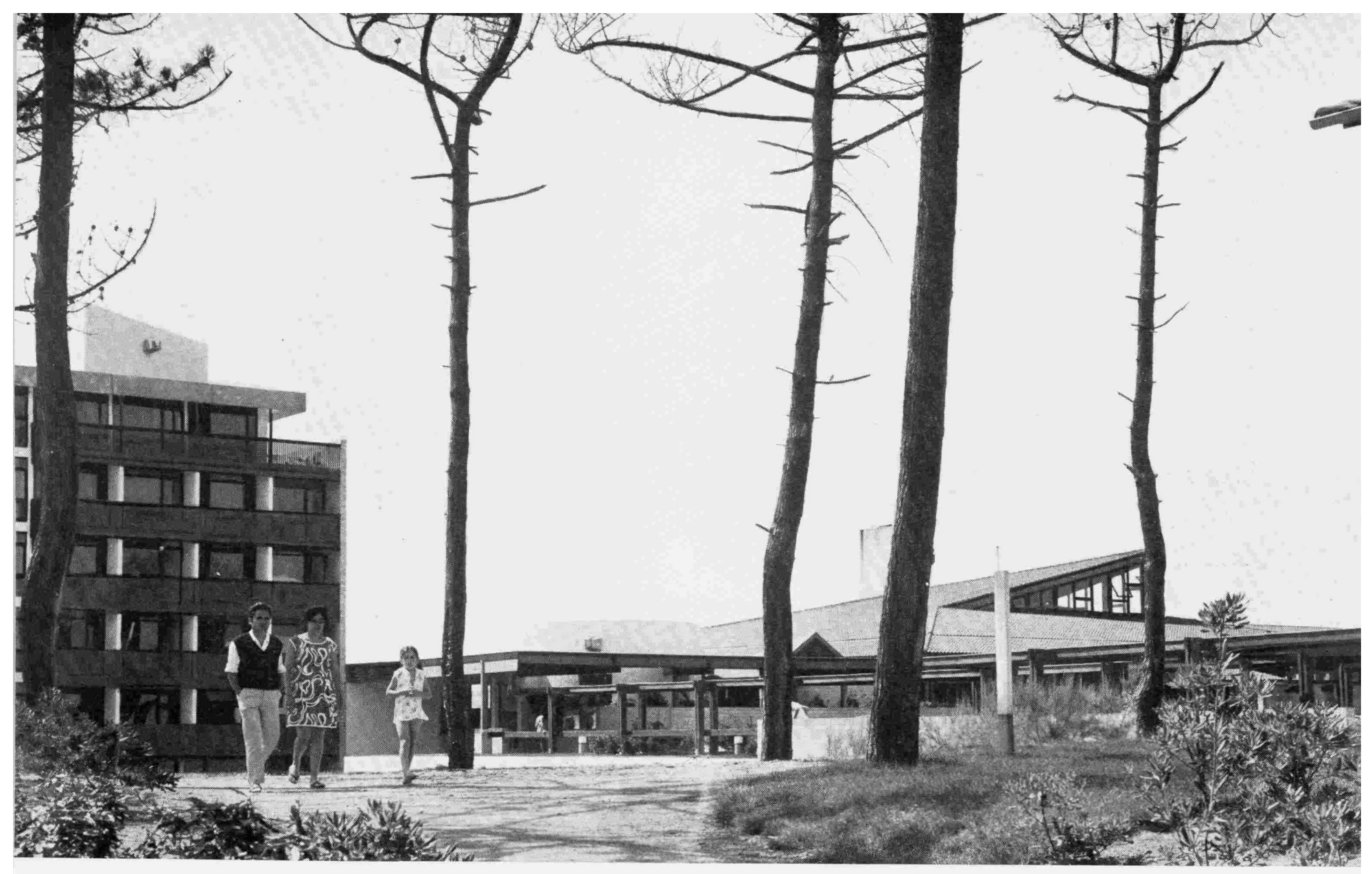

El conjunto urbanístico ha sido construido, a orillas del océano, a unos pocos kilómetros al norte de Hossegor. Está destinado preferentemente a proporcionar alojamiento a las familias que desean disfrutar allí sus vacaciones durante la temporada de verano. Comprende: 125 apartamentos de 2 habitaciones, sin cocina; 124 apartamentos de 2 habitaciones,

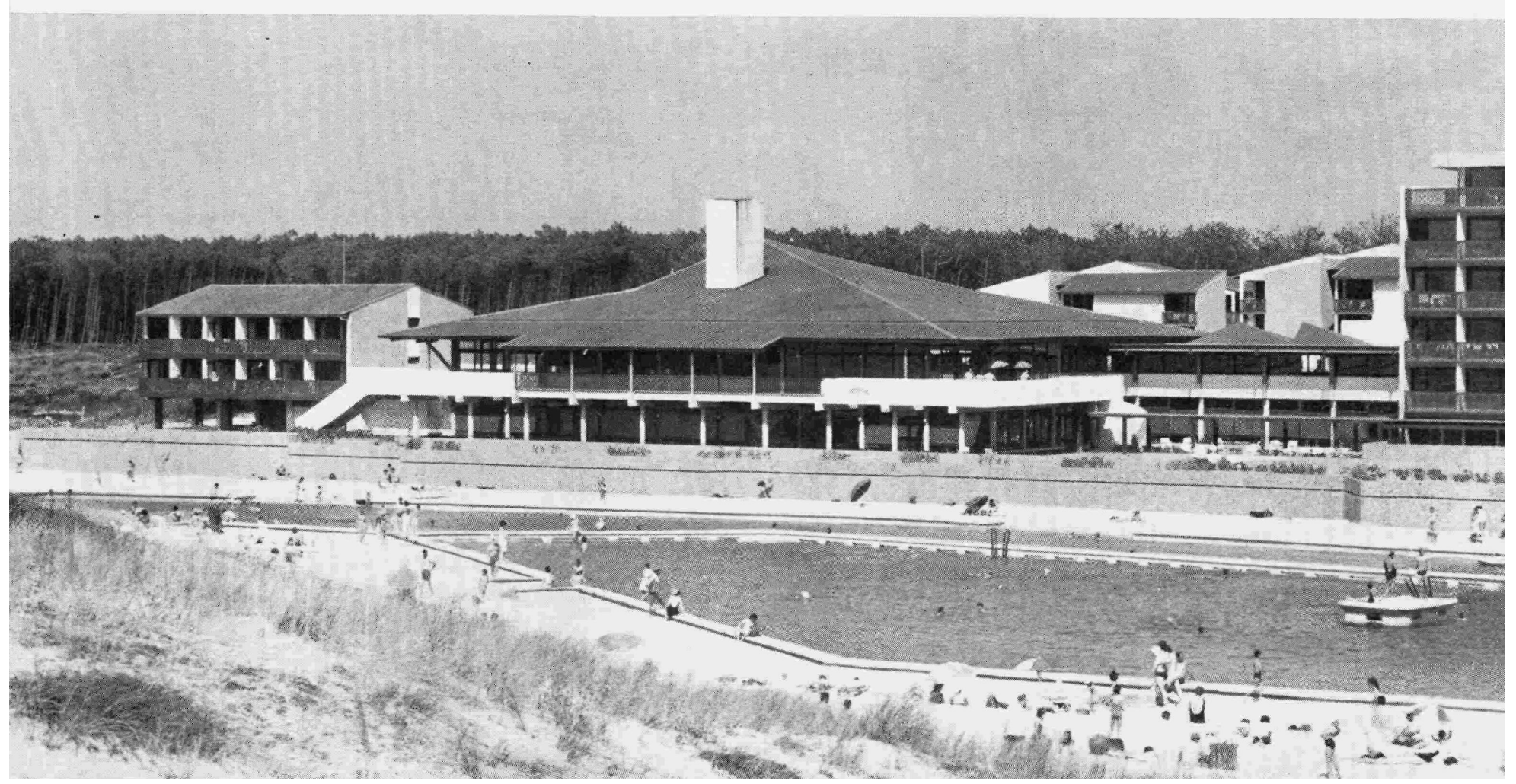


con cocina, y 50 habitaciones de hotel. En total: 1.080 camas.

Las actividades de tipo comunitario fueron agrupadas en un pabellón central muy bien equipado, en el cual se distribuyen: zonas de estar; bares; salones; restaurante, con asador para 80 cubiertos; salón para múltiples usos -celebración de espectáculos, sesiones de cine, conferencias, representaciones teatrales, veladas nocturnas, bailes y juegos-; biblioteca; televisión; una galería comercial, peluquerías de señoras y caballeros; bar de bebidas no alcohólicas, con instalaciones especiales Hi-Fi para jóvenes. También dispone de: terrazas exteriores, oficinas administrativas, restaurantes para adultos y niños, sala de juegos para niños, una gran cocina con todos los locales anexos, guardería y local para dar el biberón a los niños, 24 habitaciones para empleados, etc.

Las familias encuentran así todas las comodidades, instalaciones y servicios necesarios para disfrutar de unas vacaciones estivales agradables y con el mínimo de sujeción -incluso pueden dejar los niños, cualquiera que sea su edad, durante el día, a cargo de una institutriz-. Los edificios son utilizados también durante el resto del año para la celebración de congresos, seminarios, o para que puedan pasar temporadas o sus vacaciones aquellas personas ya retiradas de la vida activa del trabajo.
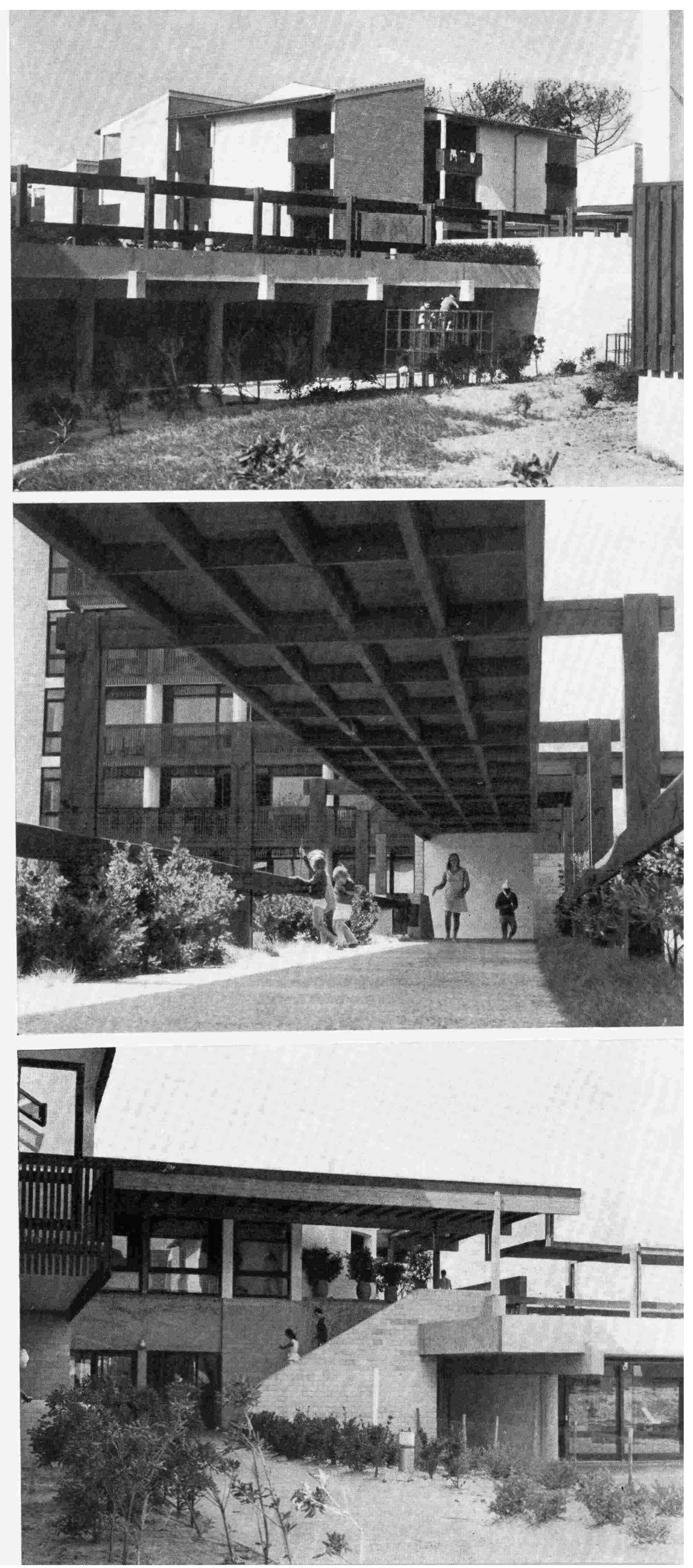


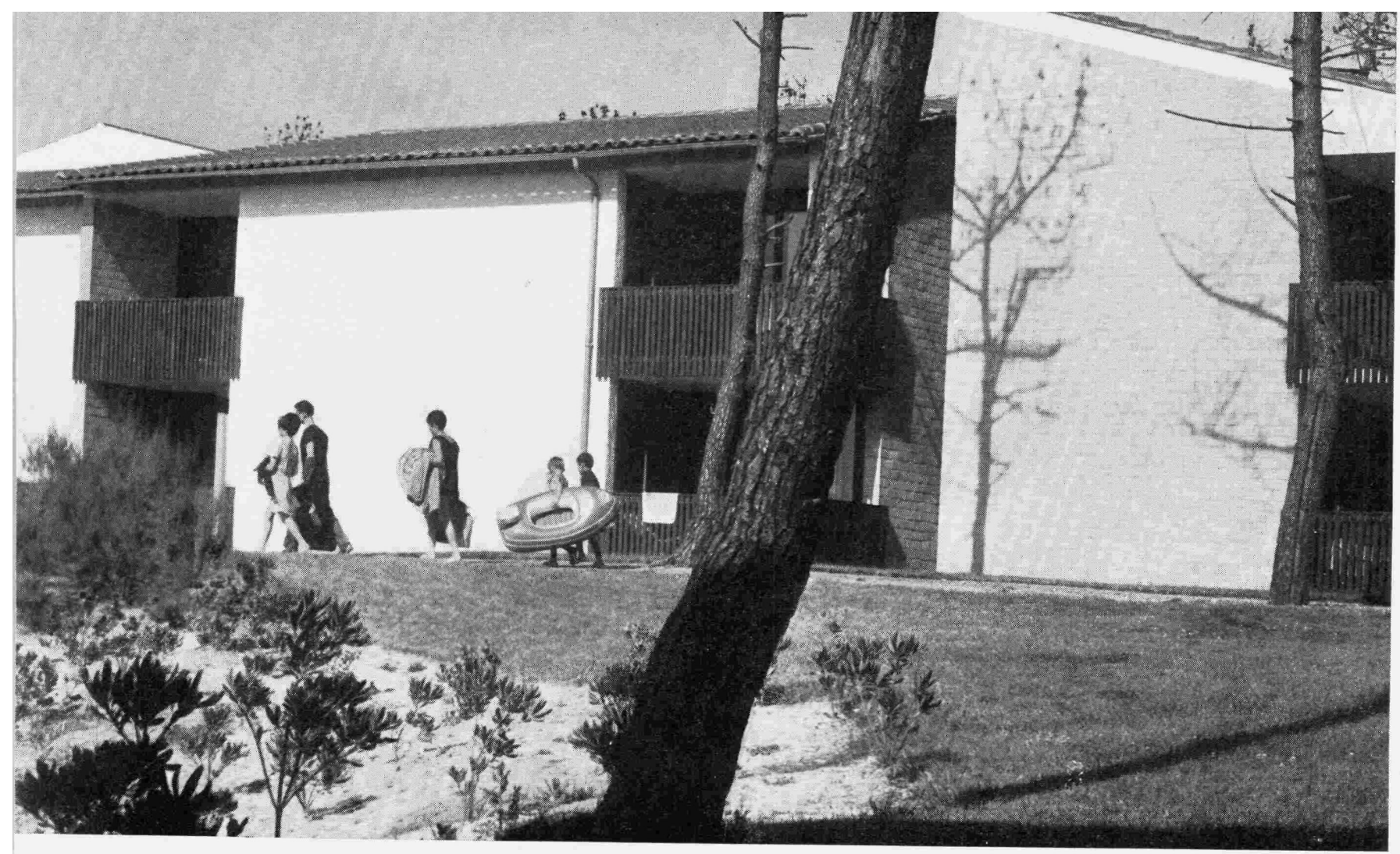

En cuanto a la organización de los diferentes volúmenes construidos, es la siguiente: de izquierda a derecha se encuentra el alojamiento, de 2 plantas, ocupado por el personal, y el pabellón central propiamente dicho.
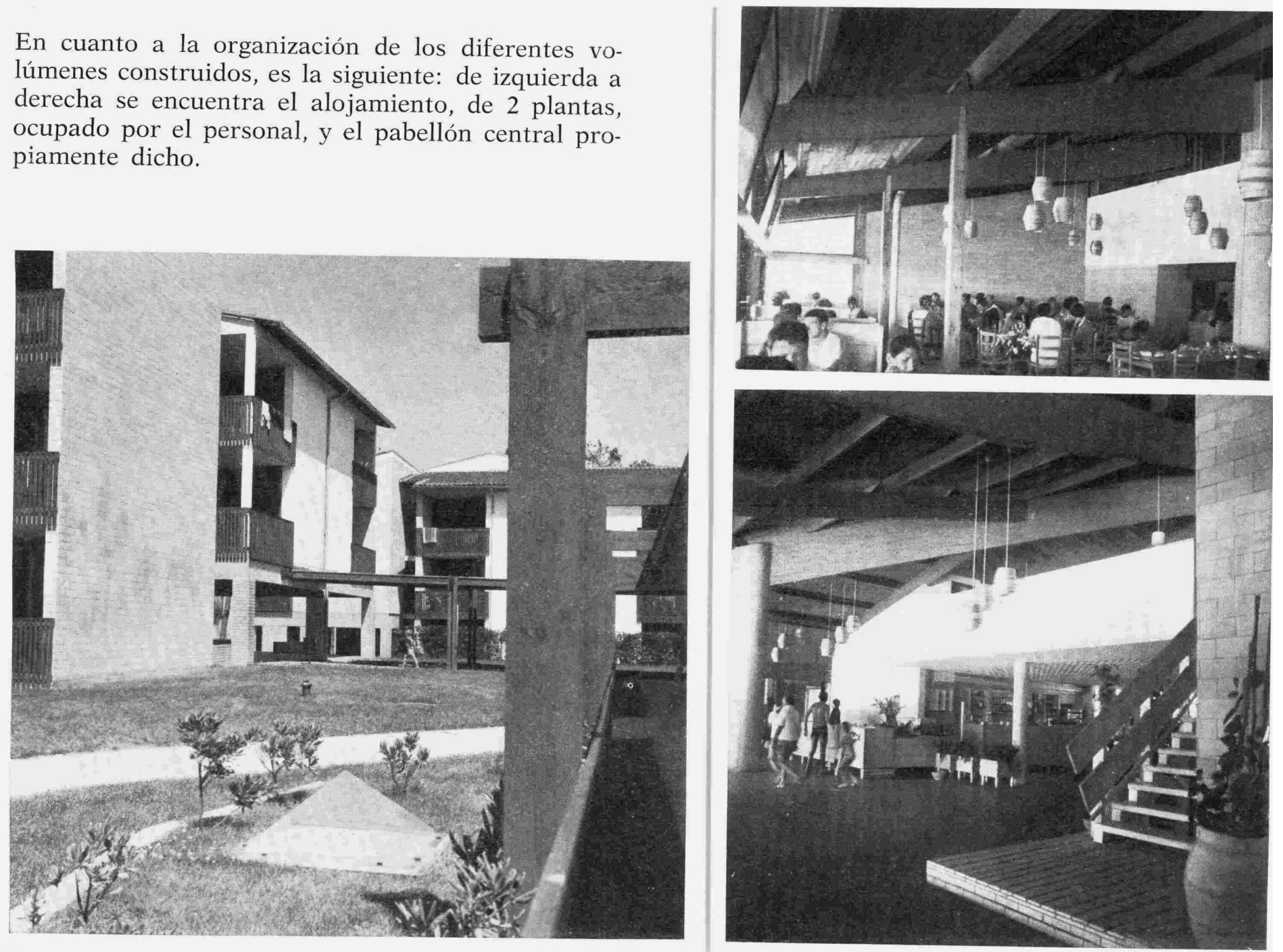


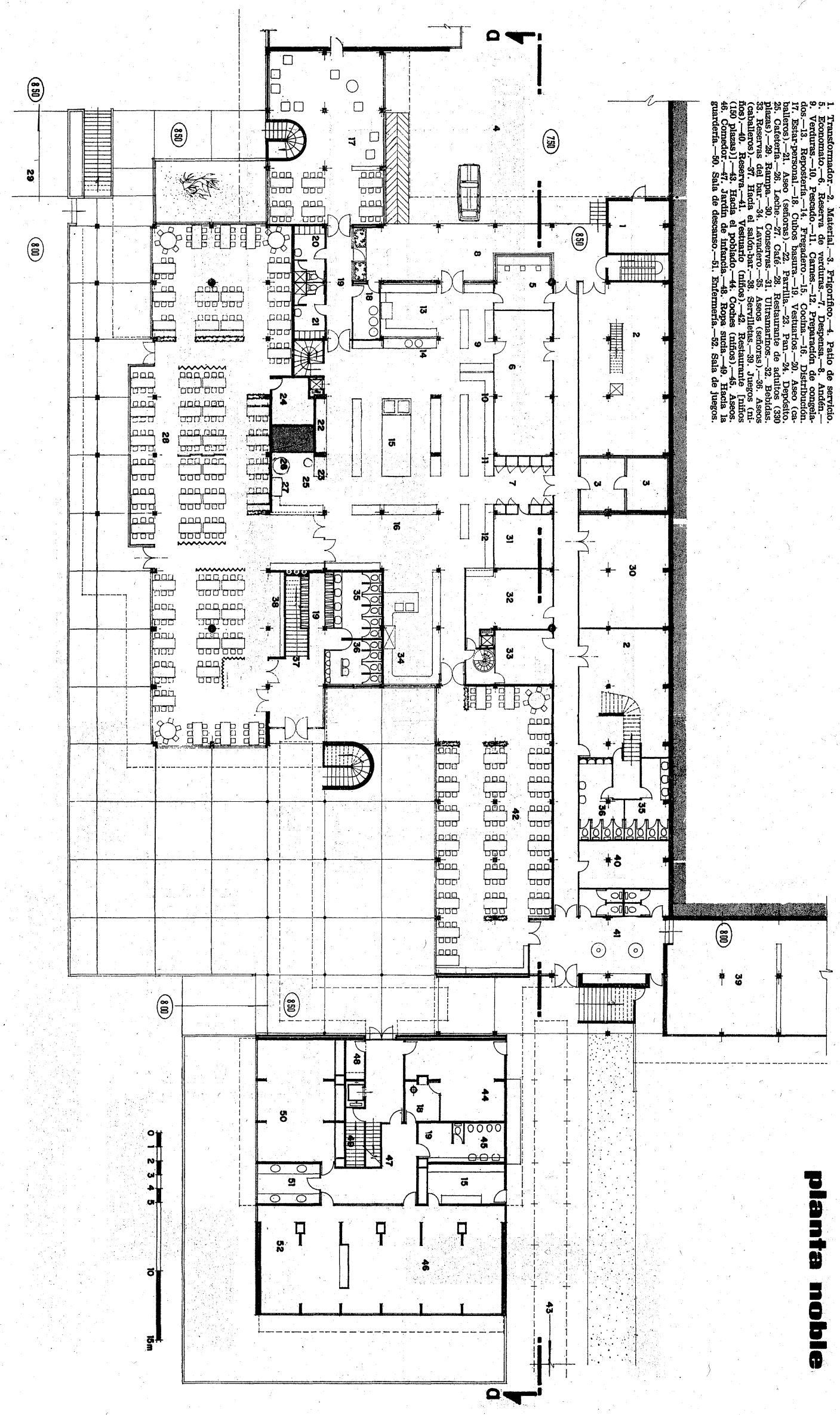




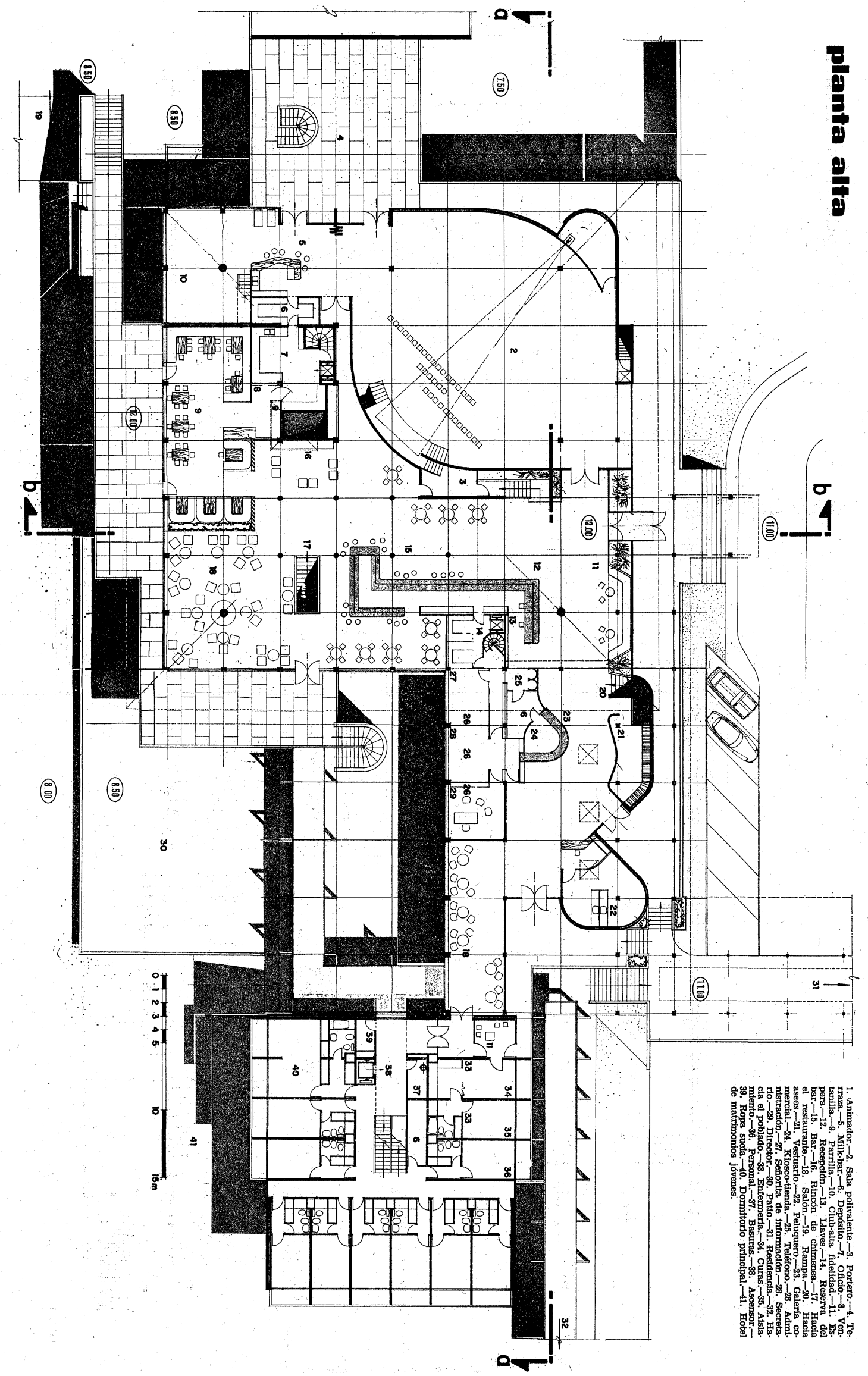



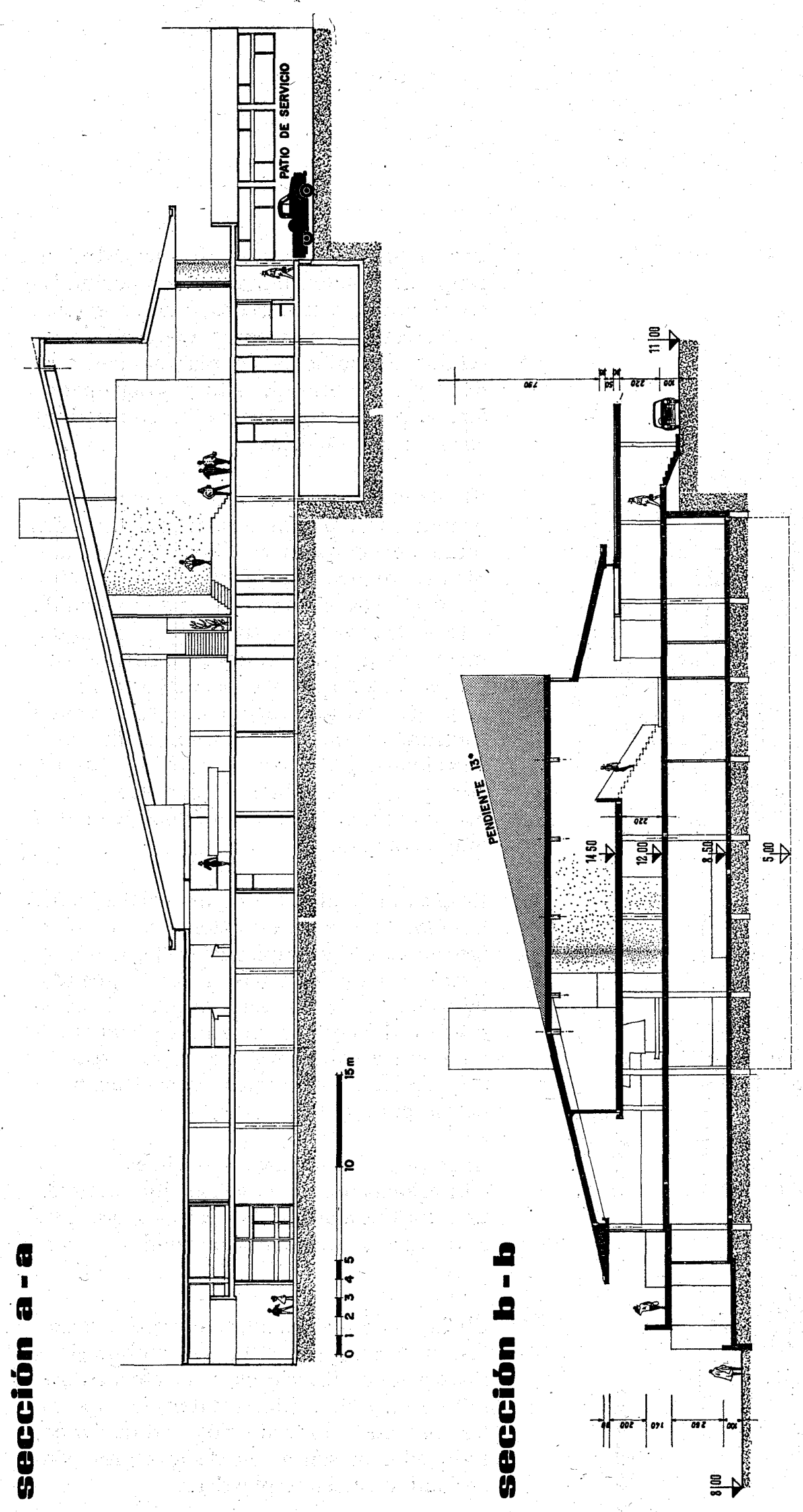

Pabeilón
centreal

Es de planta cuadrado y tiene 3 plantas de altura. En su planta baja alberga: el restaurante y la cocina; en la planta intermedia aloja: la recepción, bar, salón dedicado a múltiples usos, el restaurante, etcétera; y la planta superior contiene: las salas de televisión, biblioteca, etc.

A la derecha de dicho pabellón y en comunicación con el hotel de 6 plantas, destinado a alojar jóvenes familias, se encuentra: la galería comercial, las oficinas administrativas y las peluquerías. Entre el hotel y el pabellón se ha situado un patio de descanso que está protegido de los vientos dominantes.

Delante del citado pabellón ha sido construida una gran piscina de agua salada, toda vez que el bañarse en el mar resulta, en este lugar, extremadamente peligroso. 

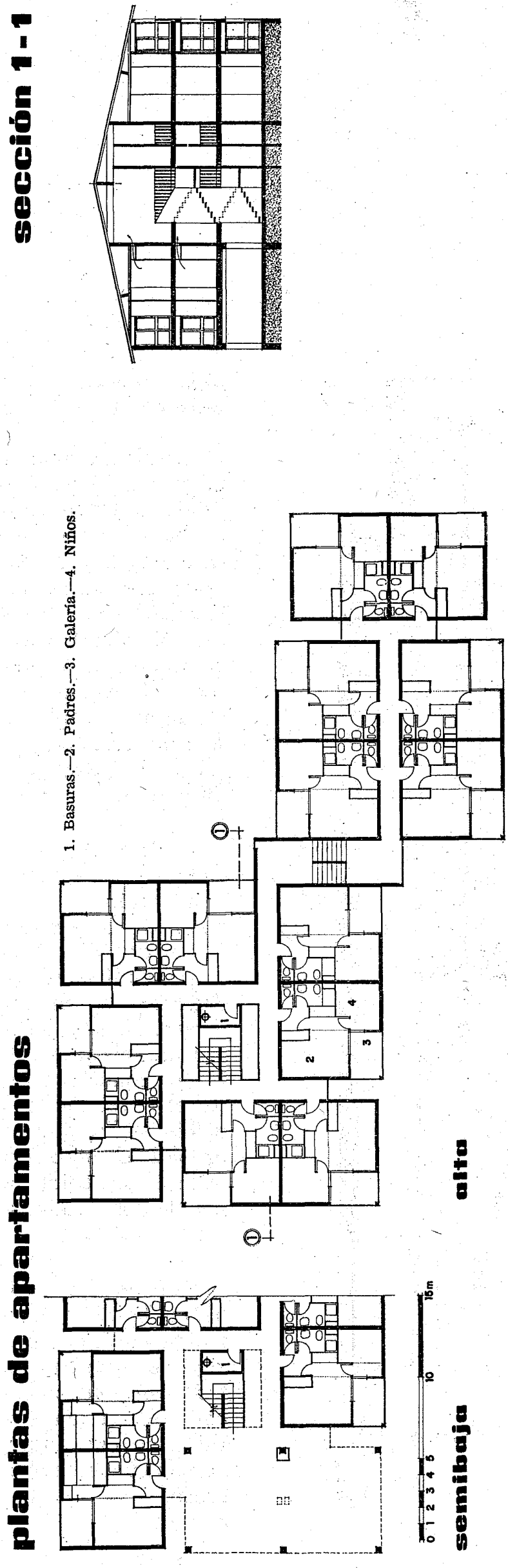

Por encima del mismo se encuentra un grupo de 124 apartamentos con cocina incorporada, y a la derecha, 125 sin cocina. Todos estos alojamientos aparecen distribuidos en edificios de planta cuadrada, de 2 y 3 plantas de altura y agrupados alrededor de pequeños patios convertidos en galerías cubiertas.

El efecto que todo ello produce en el peatón es el de un descubrimiento continuo de perspectivas diferentes, de ambientes renovados, de un juego de sombras y luces siempre distinto a medida que se avanza. De esta forma, los alojamientos -aunque completamente idénticos en cuanto a su concepción, a fin de conseguir así una repetición que se materializará en una gran economía de construcción-, gracias a su movida disposición y organización en volúmenes, siempre diferentes, les imprime una diversidad muy atractiva.

Respecto a la elección de materiales, señalaremos que tanto en exteriores como en interiores se ha empleado preponderantemente el ladrillo, zonas encaladas, calidades que, por su aspecto agradable, mutabilidad de colores al sol, resistencia y fácil entretenimiento, ha proporcionado una solución económica para el acabado de los paramentos.

$\mathrm{Al}$ emplear los mismos materiales exterior e interiormente, se ha conseguido también una continuidad en las paredes que asegura una grata homogeneidad del conjunto.

En este poblado resultan además atrayentes: la elegante sencillez del mobiliario e instalaciones interiores, $y$ el efecto obtenido a base de utilizar materiales naturales en todos los edificios, produciendo, todo ello, la sensación de una gran sinceridad y frescura plásticas. 


\section{Wiltages de vacances toumisme di Seignosse le Penom - Fmance}

Aquitaine Architectes Associés

J. R. Hebrard, A. Grésy et J. Percillier, architectes D.P.L.G.

Cet ensemble comprend: un groupement de 126 logements de 2 pièces, sans cuisines, un autre de 124 logements de 2 pièces, avec cuisines, un hôtel de 6 étages, destiné à de jeunes ménages, un pavillon central abritant les salons et les salles réservées aux activités collectives, un grand bassin d'eau de mer, des logements pour les employés, etc.

Les familles qui y vont passer leurs vacances estivales peuvent jouir de toute sorte de services de confort. En dehors des vacances d'été, les bâtiments sont utilisés pour des congrès, séminaires, ou pour des vacances de retraités.

\section{Wacation Village at Seignosse Je Pemon - France}

Aquitaine Architectes Associés

J. R. Hebrard, A. Gresy \& J. Percillier, D.P.L.G. architects

This village consists of a group of 125 flats, of two rooms each, without kitchen; a further 124 apartments, each with two rooms and a kitchen; a six storey hotel to accommodate small families; a central building containing the reception and other public rooms; a large salt water swimming pool and the houses for the staff.

Families coming to this village for their summer holidays enjoy all kinds of facilities. In the winter months this village is used for meetings and seminar activities, and it is also placed at the disposal of retired people at certain times of the year.

\section{Feriendorf in Seignose le Penon - Frumkreich}

Aquitaine Architectes Associés

J. R. Hebrard, A. Gresy und J. Percillier, Architek ten D.P.L.G.

Dieser Bebauungskomplex umfasst: eine Gruppe von 125 Appartements mit 2 Zimmern, ohne Küche; 124 Appartements mit 2 Zimmern und Küche; ein sechsgeschossiges Hotel zur Unterbringung junger Familien; ein zentraler Pavillon mit Festsälen und Nebenräumen für gemeinschaftliche Veranstaltungen; ein grosses Salzwasser-Schwimmbad; Unterkunft für die Angestellten u.s.w.

Die Familien, die hier ihre Sommerferien verbringen, kommen in den Genuss jeglicher Art von Bequemlichkeiten. Ausserhalb der Saison wird dieses Feriendorf zur Abhaltung von Kongressen und Seminarien genutzt. Es wird ebenfalls belegt von Personen im Ruhestand, die hier während gewisser Jahreszeiten wohlverdiente und geruhsame Erholung finden. 